\title{
HUBUNGAN UMUR DAN PARITAS IBU BERSALIN DENGAN KEJADIAN LASERASI DI RUMAH SAKIT PUSRI PALEMBANG TAHUN 2017
}

\author{
Rosmiarti ${ }^{1)}$, Suci Lestari ${ }^{2)}$ \\ 1) Sekolah Tinggi Ilmu Kesehatan Muhammadiyah Palembang \\ Email : rosmiarti_5474@yahoo.com \\ 2) Sekolah Tinggi Ilmu Kesehatan Muhammadiyah Palembang \\ Email : Okthaviyasusanti@gmail.com
}

\begin{abstract}
The purpose of this study was to monitor vital signs, to evaluate the origin of bleeding, and to estimate the number of advanced bleeding and to assess muscle tone at palembang pusri hospital by 2017. This research uses analytical survey method using Cross Sectional approach. The sample of this research is taken by Random Sampling.

The results of the authors were the distribution of the laceration frequency of births from 285 respondents as much as 16.6 people (556.6\%) of the lacerations and those that did not and no laceration was 123 (43.0\%). Age as many as 123 (61.8\%) who are at risk and not at risk as much as 162 (37.8\%). The parity of Pusri Palembang Hospital in 2017 from 285 respondents was 177 (61.9\%) with high risk parity and low risk parity of 108 (37.9\%). There was no correlation between maternal age and the incidence of laceration of birth canal with chi-square value obtained on education variable $p$ value $=$ $0.000<0.05$. In the age variable $p$ value $=0.000 \alpha<0.05$. On the parity variable $p$ value $=0.000 \alpha<$ 0.05. astatistically, there was no relationship between age and parity with the incidence of laceration of the birth canal
\end{abstract}

Keywords: Age, Parity, and Laceration of the birth canal

\section{PENDAHULUAN}

Perineum merupakan bagian permukaan dari pintu bawah panggul yang terletak antara vulva dan anus. Perineum terdiri dari otot dan fascia urogenitalis serta diafragma pelvis. Rupture perineum adalah robekan yang terjadi pada saat bayi lahir baik secara spontan maupun dengan menggunakan alat atau tindakan. Robekan perineum umumnya terjadi pada garis dan bisa menjadi luas apabila kepala janin lahir terlalu cepat. Robekan perineum terjadi pada hampir semua primipara (Stella dkk, 2014). Laserasi perineum adalahrobekan yang terjadi di garis tengah dan bias menjadi luas apabila kepala janin lahir terlalu cepat (Cut Rosmawan, 2011).

World Health Organization (WHO), pemerintah melaksanakan strategi utama adalah memberi pertolongan persalinan yang diberikan tenaga kesehatan, kedua mengupayakan komplikasi dan perdarahan ibu saat mengandung dan dapat ditangani, ketiga mengupayakan pencegahan kehamilan yang tidak diinginkan. Mengenai target

Volume 5 Nomor 2
menurunkanAngka Kematian Ibu (AKI) menjadi $125 / 100.000$, agaknya sulit mencapai target tersebut (Depkes RI, 2004).

Hingga saat ini bila dibandingkan negaranegara Assosiation Of South Asia Nation (ASEAN), Angka kematian ibu (AKI) di Indonesia menempati posisi paling tinggi yaitu sebanyak 307 pada tahun 2002. Penyebab AKI tinggi ada dua faktor penyebab, yaitu medis dan akses ke pelayanan kesehatan.

Berdasarkan Survei Demografi dan Kesehatan Indonesia (SDKI) 2007, Angka Kematian Ibu (AKI) di Indonesia masih berada pada angka 228 per 100.000 kelahiran hidup Demikian pula angka kematian bayi (AKB) berjumlah 34 per 1000 kelahiran hidup, Angka Kematian Neonatal (AKN) berjumlah 19 per 1000 kelahiran hidup, dan Angka Kematian Balita (AKABA) berjumlah 44 per 1000 kelahiran hidup (Depkes RI, 2009).

Salah satu upaya penurunan $A K I$ untuk sektor kesehatan adalah dengan meningkatkan cakupan pertolongan persalinan oleh tenaga kesehatan paling sedikit $90 \%$ pada tahun 2010. 
Dari seluruh persalinan penyebab kematian ibu adalah perdarahan yang disebabkan oleh atonia uteri 50-60\%, retensio plasenta 16$17 \%$, sisa plasenta $23-24 \%$, laserasi jalan lahir 4-5\%, kelainan darah 0,5-0,8\%, perdarahan pasca persalinan sering disebabkan oleh robekan perineum, selain atonia uteri. Robekan perineum biasanya ringan, tetapi kadang-kadang terjadi luka yang luas dan berbahaya (Rahmat, 2010).

Berdasarkan data Dinas Kesehatan Sumatera Selatan kasus terjadilaserasi jalan lahir untukdi Provinsi Sumatera Selatan tahun pada tahun 2008 sebanyak 88,16\%, pada tahun 2009 sebanyak 72,82\%, sebanyak 2012 sebanyak91,78\%. (Dinkes Sumsel,2012).

Cukup laserasi jalan lahir untuk Rumah Sakit Pusri Kota Palembang tahun 2010 sebanyak $21,74 \%$.

Menurut Melly Astuti (2008), didapatkan ibu yang memiliki paritas tinggi sebesar 246 orang $(71,1 \%)$ dan pada ibu yang memiliki paritas rendah sebesar 100 orang $(28,9 \%)$. Dari hasil uji Chi-Square menunjukan ada hubungan bermakna antara paritas ibu bersalin dengan kejadian robekan perineum

Menurut Siti Dwi Endriani (2012) Menunjukan bahwaterjadinya laserasi perineum dan tidak laserasi perineum berdasarkan umur pada ibu bersalin normal yaitu dari 29 ibu yang melahirkan bayi dengan umur $<20$ atau $>30$ tahun diantaranya 14 responden $(24,2 \%)$ mengalami laserasi perineum dan 13 responden $(22,4 \%)$ tidak mengalami laserasi perineum. Sedangkan dari 29 ibu bersalin yang melahirkan bayi dengan umur 20-30 tahun yaitu dari 15 responden $(25,9 \%)$ mengalami laserasi perineum dan 16 responden $(27,6 \%)$ tidak mengalami laserasi perineum. Hasil uji chi square menunjukan nilai $\mathrm{p}=0,792$ yang berarti $\mathrm{p}>0,05$ bahwa tidak ada hubungan antara umur dengan kejadian laserasi jalan lahir.

\section{METODE PENELITIAN}

Penelitian menggunakan metode kuantitatif bersifat analitik dengan menggunakan rancangan penelitian cross sectional merupakan untuk mempelajari dinamika korelasi dengan efek cara pendekatan, observasi atau pengumpulan sekaligus. Dimana variabel independent (usia, paritas) serta variabel dependent (kejadian laserasi jalan lahir) dikumpulkan dalam waktu yang bersamaan.

Populasi dalam penelitian ini adalah semua ibu bersalinyang tercatat di Rekam Medik Rumah Sakit Pusri dari 1 Januari - 30 September yang berjumlah $1000 \mathrm{ibu}$ bersalin normal tahun 2017. Untuk kecukupan data yang harus di dapat oleh penelitian Random sampling dimana sampel yang ada diambil secara acak sederhana dengan teknik pengambilan sampel Random Sampling sistematis menggunakan interval.

\section{HASIL PENELITIAN}

Tabel 1.

Distribusi Frekuensi Responden Berdasarkan

Kategori Riwayat Umur Di Rumah Sakit Pusri Palembang Tahun 2017

\begin{tabular}{llcc}
\hline No & $\begin{array}{l}\text { Riwayat } \\
\text { Umur }\end{array}$ & $\begin{array}{c}\text { Frekuensi } \\
\text { (f) }\end{array}$ & $\begin{array}{c}\text { Peresentasi } \\
(\%)\end{array}$ \\
\hline $\mathbf{1}$ & Resiko & 68 & 23.9 \\
$\mathbf{2}$ & Tidak Resiko & 216 & 76.1 \\
& Jumlah & 284 & 100.0 \\
\hline
\end{tabular}

Tabel 2.

Distribusi Frekuensi Responden Berdasarkan

Kategori Riwayat Paritas di Rumah Sakit Pusri Palembang Tahun 2017

\begin{tabular}{llcc}
\hline No & Riwayat Paritas & $\begin{array}{c}\text { Frekuensi } \\
(\mathrm{f})\end{array}$ & $\begin{array}{c}\text { Peresentasi } \\
(\%)\end{array}$ \\
\hline $\mathbf{1}$ & Resiko tinggi & 193 & 67.7 \\
$\mathbf{2}$ & Resiko rendah & 92 & 32.3 \\
& Jumlah & 285 & 100.0 \\
\hline
\end{tabular}

Tabel 3.

Distribusi Frekuensi Responden Berdasarkan Kategori Riwayat Umur Di Rumah Sakit Pusri Palembang Tahun 2017

\begin{tabular}{lccc}
\hline No & Paritas & $\begin{array}{c}\text { Frekuensi } \\
(\mathrm{f})\end{array}$ & $\begin{array}{c}\text { Peresentasi } \\
(\%)\end{array}$ \\
\hline $\mathbf{1}$ & Ya & 80 & 28.1 \\
$\mathbf{2}$ & Tidak & 205 & 71.9 \\
& Jumlah & 285 & 100.0 \\
\hline
\end{tabular}


Tabel 4

Hubungan antara Usia Dengan Kejadian Laserasi Jalan Lahir di Rumah Sakit Pusri Palembang Tahun 2017.

\begin{tabular}{|c|c|c|c|c|c|c|c|}
\hline \multirow[t]{3}{*}{ Usia } & \multicolumn{4}{|c|}{$\begin{array}{l}\text { Pelaksanaan senam } \\
\text { hamil }\end{array}$} & \multirow{2}{*}{\multicolumn{2}{|c|}{ Jumlah }} & \multirow[t]{3}{*}{$\begin{array}{l}\rho \\
\text { Value }\end{array}$} \\
\hline & \multicolumn{2}{|c|}{$\mathrm{Ya}$} & \multicolumn{2}{|c|}{ Tidak } & & & \\
\hline & $\mathrm{N}$ & $\%$ & $\mathrm{~N}$ & $\%$ & $\mathrm{~N}$ & $\%$ & \\
\hline Resiko & 74 & 60,1 & 49 & 39,8 & 123 & 100 & 0.324 \\
\hline $\begin{array}{l}\text { Tidak } \\
\text { Resiko }\end{array}$ & 88 & 54,3 & 74 & 45,6 & 162 & 100 & \\
\hline Total & 162 & 56,3 & 123 & 43,1 & 285 & 100 & \\
\hline
\end{tabular}

Tabel 5

Hubungan Antara Paritas dengan Kejadian Laserasi Jalan Lahir di Rumah Sakit Pusri Palembang Tahun 2017.

\begin{tabular}{|c|c|c|c|c|c|c|c|}
\hline \multirow{3}{*}{ Paritas } & \multicolumn{4}{|c|}{ Pelaksanaan senam hamil } & \multirow{2}{*}{\multicolumn{2}{|c|}{ Jumlah }} & \multirow{3}{*}{$\begin{array}{l}\rho \\
\text { Value }\end{array}$} \\
\hline & \multicolumn{2}{|l|}{$\mathrm{Ya}$} & \multicolumn{2}{|c|}{ Tidak } & & & \\
\hline & $\mathrm{N}$ & $\%$ & $\mathrm{n}$ & $\%$ & $\mathrm{~N}$ & $\%$ & \\
\hline $\begin{array}{l}\text { Resiko } \\
\text { Tinggi } \\
\text { primi- } \\
\text { para }\end{array}$ & 94 & 53,1 & 83 & 46,9 & 177 & 100 & 0.000 \\
\hline $\begin{array}{l}\text { Resiko } \\
\text { Rendah } \\
\text { Multi- } \\
\text { para }\end{array}$ & 68 & 62,9 & 40 & 37 & 108 & 100 & \\
\hline Total & 84 & 16,8 & 123 & 47,6 & 285 & 100 & \\
\hline
\end{tabular}

Berdasarkan distribusi,frekuensi diatas, menunjukan bahwa dari 285 responden terdapat sebanyak $68(23.9 \%)$ umur yang beresiko mengalami laserasi dan responden yang tidak beresiko mengalami laserasi sebanyak 216 $(76.1 \%)$

Berdasarkan distribusi frekuensi diatas, menunjukan bahwa dari 285 responden terdapat sebanyak $193(67.7 \%)$ paritas yang beresiko mengalami laserasi dan responden yang tidak beresiko mengalami laserasi sebanyak 92 $(23.3 \%)$

Berdasarkan distribusi frekuensi diatas, menunjukan bahwa dari 285 responden terdapat sebanyak $80(27.9 \%)$ yang beresiko mengalami laserasi dan responden yang tidak beresiko mengalami laserasi sebanyak 205 (99.3\%).

Berdasarkan hasil dari $68 \mathrm{ibu}$ bersalin dengan umur resiko terdapat $75 \%$ (51 orang) yang tidak mengalami laserasi jala lahir dan $25 \%$ (17 orang) yang mengalami laserasi jalan lahir. Dari $25 \%$ orang ibu bersalin dengan umur tidak resiko 152 orang $(71,1 \%)$ responden yang tidak mengalami laserasi jalan lahir sebanyak 62 orang $(28,8 \%)$ yang mengalami laserasi jalan lahir.

Berdasarkan hasil dari 193 orang ibu bersalin dengan paritas resiko tinggi terdapat 137 orang $(70.9 \%)$ ibu yang tidak mengalami laserasi jalan lahir dan $56(29.1 \%)$ orang ibu yang tidak mengalami laserasi jalan lahir. Selanjutnya dari 92 orang ibu bersalin dengan paritas resiko rendah terdapat $73,9 \%$ (68 orang) yang tidak mengalami laserasi jalan lahir dan 26.1\% (24 orang) yang mengalami laserasi jalan lahir.

\section{PEMBAHASAN}

\section{Hubungan Usia dengan kejadian laserasi jalan lahir}

Hasil uji statistic chi-square dapat diketahui $\rho$ Value $=0,646>\alpha 0,05$, hal ini menunjukan bahwa tidak ada hubungan yang bermakna antara umur ibu dengan kejadian laserasi jalan lahir di Rumah Sakit Pusri Palembang Tahun 2017.

Umur adalah jumlah hari, bulan dan tahun yang telah dilalui sejak lahir sampai dengan waktu tertentu. Pada usia reproduktif (20-30 tahun) terjadi kesiapan respon maksimal baik dalam hal mempelajari sesuatu atau dengan menyesuaikan hal-hal tertentu dan setelah itu sedikit demi sedikit menurun dengan bertambahnya umur. Selain itu pada usia reproduktif mereka lebih terbuka pada orang lain dan biasanya mereka akan saling bertukar pengalaman tentang yang sama yang pernah merek alami.

Dalam kurung reproduksi sehat dikenal bahwa usia aman untuk kehamilan dan persalinan adalah 20-30 tahun. Hal ini dikarnakan pada usia dibawah 20 tahun, fungsi reproduksi seorang wanita belum berkembang dengan sempurna, sedangkan pada usia 35 tahun keatas fungsi reproduksi seorang wanita sudah mengalami penurunan dibandingkan fungsi reproduksi normal (Stella dkk, 2014).

Penelitian ini sejalan Siti dwi Endriani (2012) dengan judul Hubungan Umur, Paritas, Dan Berat Badan Bayi Lahir Dengan Kejadian Laserasi Jalan Lahir Di Bidan Praktek Swasta Hj. Sri Wahyuni, S.SiT Menunjukan bahwa terjadinya laserasi perineum dan tidak laserasi perineum berdasarkan umur pada ibu bersalin normal yaitu dari 29 ibu yang melahirkan bayi 
dengan umur $<20$ atau $>30$ tahun diantaranya 14 responden $(24,2 \%)$ mengalami laserasi perineum dan 13 responden $(22,4 \%)$ tidak mengalami laserasi perineum. Sedangkan dari $29 \mathrm{ibu}$ bersalin yang melahirkan bayi dengan umur 2030 tahun yaitu dari 15 responden $(25,9 \%)$ mengalami laserasi perineum dan 16 responden $(27,6 \%)$ tidak mengalami laserasi perineum. Hasil uji chi square menunjukan nilai $\mathrm{p}=0,792$ yang berarti $p>0,05$ bahwa tidak ada hubungan antara umur dengan kejadian laserasi jalan lahir.

Dari hasil penelitian, peneliti berasumsi bahwa tidak ada hubungan antara umur dengan kejadian laserasi jalan lahir, karena laserasi jalan lahir belum tentu disebabkan oleh umur, bias juga disebabkan oleh faktor bayi, seperti berat badan bayi dan kelainan letak, kemudian bisa juga disebabkan faktor penolong seperti cara memimpin mengejan yang salah dan keterampilan menahan perineum saat ekspulsi kepala.

\section{Hubungan Paritas dengan kejadian jalan lahir}

Dapat diketahui bahwa dari 193 orang ibu bersalin dengan paritas resiko tinggi terdapat 137 orang $(70.9 \%)$ ibu yang tidak mengalami laserasi jalan lahir dan 56 (29.1\%) orang ibu yang tidak mengalami laserasi jalan lahir. Selanjutnyadari 92 orang ibu bersalin dengan paritas resiko rendah terdapat $73,9 \%$ (68 orang) yang tidak mengalami laserasi jalan lahir dan 26.1\% (24 orang) yang mengalami laserasi jalan lahir

Dari uji statistic chi-square dapat diketahui $\rho$ Value $=0,709<\alpha 0,05$, hal ini menunjukan bahwa ada hubungan yang bermakna antara paritas ibu dengan kejadian laserasi jalan lahir di Rumah Sakit Pusri Palembang Tahun 2017.

Paritas adalah jumlah anak yang dilahirkan oleh seseorang ibu baik hidup maupun mati. Paritas mempunyai pengaruh terhadap kejadian rupture perineum. Pada ibu dengan paritas satu atau ibu primipara memiliki risiko lebih besar untuk mengalami robekan perineum daripada ibu dengan paritas lebih dari satu. Hal ini dikarenakan jalan lahir yang belum pernah dilalui oleh kepala bayi sehinggaotot-otot perineum belum meregang (Stella dkk, 2014).

Penelitian ini tidak sejalan dengan peneliti yang dilakukan oleh Menurut Melly Astuti Hubungan Umur, Paritas, Dan Berat Badan Bayi Lahir Dengan Kejadian Laserasi Jalan Lahir di
RS Jiwa Prof. Dr. V.L Ratnbuysang Manado Tahun 2008, didapatkan ibu yang memiliki paritas tinggi sebesar 246 orang $(71,1 \%)$ danpada ibu yang memiliki paritas rendah sebesar 100 orang $(28,9 \%)$. Dari hasil uji ChiSquare menunjukan ada hubungan bermakna antara paritas ibu bersalin dengan kejadian robekan perineum.

Berdasarkan hasil penelitian, peneliti berasumsi bahwa paritas tidak mempengaruhi kejadian laserasi jalan lahir karena pengetahuan dan sikap ibu terhadap cara mengejan yang baik juga mempngarui kejadian laserasi jalan lahir.

\section{SIMPULAN DAN SARAN Simpulan}

1. Tidak terdapat hubungan paritas dengan kejadian laserai jalan lahir pada ibu bersalin di Rumah Sakit Pusri Palembang tahun 2017, dari hasil penelitian diketahui $\rho$ value $=0,000$ $<\alpha 0,05$, artinya tidak ada hubungan yang bemakna antara paritas dengan kejadian lasirasi jalan lahir.

2. Tidak terdapaat hubungan antara umur ibu dengan kejadian laserasi jalan lahir di Rumah Sakit Pusri Palembang tahun 2017, dari hasil penelitian diketahui $\rho$ value $=0,000<\alpha 0,05$, artinya tidak ada hubungan yang bemakna antara umur dengan kejadian laserasi jalan lahir pada ibu bersalin.

\section{Saran}

1. Bagi Rumah Sakit Pusri Palembang

Diharapkan bagi Rumah Sakit Pusri Palembang untuk melakukan penyuluhan dan meningkatkan pelayanan pada ibu yang akan melakukan senam hamil terutama pada ibu usia beresiko dan pendidikan rendah.

2. Bagi STIKES Pembina Palembang Diharapkan agar pihak pendidikan dapat meningkatkan fasititas seperti perpustakaan yangharus dilengkapi buku-buku mengenai kesehatan sebagai bahan referensi untuk pembuatan Karya Tulis Ilmiah.

3. Bagi Peneliti Lainnya

Diharapkan agar dapat melakukan penelitian lanjutan mengenai pelaksanaan senam hamil dengan variabel yang lebih bervariasi dan sampel yang lebih besar. 


\section{REFERENSI}

Asrinah. 2010. Faktor-faktor Yang Mempengaruhi Persalinan. Jakarta. Salemba Medika

Cut Rosmawan. 2011. Faktor-Faktor Yang Mempengaruhi Terjadinya Laserasi Pada Persalinan Normal di Puskesmas Tanah Jambo Aye Panton Labu. Banda Aceh: TenagaPengajar Pada STIKes U'Budiyah

Enkin. 2000. Asuhan Kebidanan. Jakarta. P.T Bina Pustaka

Jones. 2016. Manajemen Kebidanan Terlengkap. Jakarta : Trans Info Media.

Kampono. 2008. Manajemen Kebidanan. TIM 2016. Jakarta :Pustaka Nasional.

Maemunah. 2016. Manajemen Kebidanan. Jakarta : Trans Info Media.

Notoatmodjo. 2012. Metodelogi Penelitian Kesehatan. Jakarta :SalembaMedika

Prawirohardjo. 2014. Ilmu Kebidanan. Jakarta :P.T BinaPustaka.

Rahmat. 2010. Resiko Persalinan dan Penanganannya. Jakarta. SalembaMedika

Rohani dkk. 2013). Asuhan Kebidanan Pada Masa Persalian. Jakarta: Salemba Medika.

Siti Dwi Endriani, dkk. 2012. Jurnal Hubungan Umur, Paritas dan Berat Badan Bayi Lahir dengan Kejadian Laserasi Perineum di Bidan Praktek Swasta Hj. Sri Wahyuni, S.SiT. Semarang :Universitas Muhamamdiyah

Stella Dkk, (2014), Faktor-Faktor Yang Berhubungan Dengan Robekan Jalan Lahir Pada Ibu Bersalin. Manado :Jurusan Kebidanan Poltekes Kemenkes.

Stiladi. 2012. Metode Penelitian Kesehatan. Jakarta. Salemba Medika

WHO. 2014. Profil Kesehatan Indonesia. http: // word heralth organitation. com.id. 